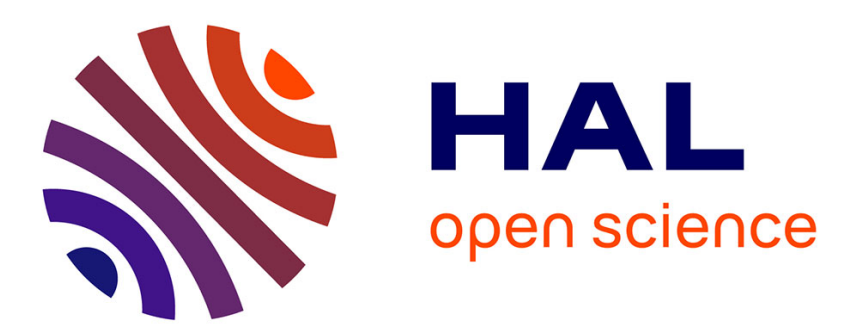

\title{
Compaction properties of dry granulated powders based on Drucker-Prager Cap model
}

Lucia Perez-Gandarillas, Alon Mazor, Olivier Lecoq, Abderrahim Michrafy

\section{To cite this version:}

Lucia Perez-Gandarillas, Alon Mazor, Olivier Lecoq, Abderrahim Michrafy. Compaction properties of dry granulated powders based on Drucker-Prager Cap model. Powder Technology, 2018, 337, pp.43-50. 10.1016/j.powtec.2017.12.057 . hal-01700665

\section{HAL Id: hal-01700665 \\ https://hal.science/hal-01700665}

Submitted on 7 Nov 2019

HAL is a multi-disciplinary open access archive for the deposit and dissemination of scientific research documents, whether they are published or not. The documents may come from teaching and research institutions in France or abroad, or from public or private research centers.
L'archive ouverte pluridisciplinaire HAL, est destinée au dépôt et à la diffusion de documents scientifiques de niveau recherche, publiés ou non, émanant des établissements d'enseignement et de recherche français ou étrangers, des laboratoires publics ou privés. 


\title{
Compaction properties of dry granulated powders based on Drucker-Prager Cap model
}

\author{
L. Perez-Gandarillas *, A. Mazor, O. Lecoq, A. Michrafy \\ Université de Toulouse, Mines Albi, CNRS, Centre RAPSODEE, Albi, France
}

\section{A B S T R A C T}

Dry granulation by roll compaction is a process of size enlargement used to produce granules with a good flowability for further die compaction process. To gain in the understanding of how granulated powders behave during die compaction and why they exhibit different behaviors different from those showed by the feed powder, the main material parameters proposed in Drucker-Prager Cap (DPC) model, were determined for MCC101 powder and two granule sizes obtained from roll-compacted ribbons. For that, the standard procedure calibration of DPC was used.

Results showed that all the material properties are density-dependent and the properties of feed powder are higher than those of granulated powder. Moreover, the yield hardening function showed a decrease with the increase of the granule size, which highlighted that the granules of MCC 101 exhibit a softer work hardening than feed powders. Overall, the granules have smaller yield surface than the feed powder. Particularly, it was found, for both granule sizes and the MCC 101 powder, an overlapping of shear failure line at high relative density. Nevertheless, at low density, the cohesion was affected by the roll compaction of MCC 101, but no variation was observed for the internal friction angle. The obtained results are in agreement with the literature, where the granules were prepared from mini-tablets rather than from roll-compaction. However, some discrepancies were highlighted.

Keywords:

Roll compaction

Granules

Die compaction

Drucker-Prager cap (DPC) model

\section{Introduction}

To improve the flowability of powders, dry granulation by rollcompaction process is often used in the pharmaceutical industry [1]. The process consists of compacting powders between two counterrotating rolls to produce ribbons that will be subsequently milled into granules. The obtained granules are tableted for oral dosage. The properties of the granules such as particle size distribution and porosity are determined by the quality of the compacted ribbons. The resulting structural and mechanical properties of the granules are particularly essential in the understanding of the die-compaction process and the resulting tablet properties.

It has been reported in the literature that, in comparison with the powders before granulation, the granulated powders by roll compaction exhibit different behaviors in die compaction. These differences were observed in the compressibility, the compactability or the tensile strength [2-5]. Such behavior was showed not only for pharmaceutical powders but also for ceramic powders and seems to be not limited to the dry granulation by roll compaction process $[6,7]$. Nevertheless, there is no credible procedure able to explain the above challenge. An

\footnotetext{
* Corresponding author

E-mail address: lucia.gandarillas@mines-albi.fr (L. Perez-Gandarillas).
}

attempt to explore the differences of compaction behavior for raw and granulated material is to conduct a study on the behavior, under stressing, of the main parameters of particulate solids proposed by the Drucker-Prager Cap (DPC) model. The advantage of the DPC model is the explicit recognition of the three dimensional character of the stress during compaction [16], compared to the uniaxial compaction tests.

Recently, Mitra et al. [8] analyzed the difference in the compaction behavior of MCC dry granules (mini-tablets) with the raw material and mini-tablets as dry granules. The minitablets were monodisperse in both size and solid fraction. The analysis was based on the calibration of the parameters of the Drucker-Prager Cap model. Results showed that both virgin MCC and mono-disperse granules required the same in-die compaction stress state to achieve a certain tablet density. It was also found a decrease of the cohesion of tablets formed from the granules in comparison with the virgin powder. They stated that the reduced strength of tablets formed from granules is due to the less uniform microstructure formed than as the result of strain hardening. However, in this study, the granules were small mono-disperse cylindrical compacts and they probably have different compaction behavior from that resulting from granules produced with roll-compaction, where the shape and the microstructure are certainly different.

The aim of this work was to explore the difference in the compaction behavior of raw material and granules prepared by roll compaction/dry 
granulation process. The study was conducted on microcrystalline cellulose powder (MCC 101), and the analysis was based on the comparison of the main material parameters proposed by the DPC model. The effect of the granule sizes as one influencing parameter on the compaction was also considered in this study.

\section{Powder compaction behavior}

To analyze the compaction behavior of both raw and granulated material, different properties can be compared for similar density's state. These can include, the tablet strength (compactability), the compressibility (volume reduction under pressure) or the stress transmission during the compaction. Instead of characterizing the behavior for a simple compressive or extensive stress, another manner is to characterize the elastic and plastic behavior of the material based on the determination of a yield surface and how this yield surface can expand or contract according to the loading state. The domain defined under the surface characterizes any stress state under which the material can behave elastically. However, for any stress that can expand the current domain, the deformation of the material is then irreversible (plastic behavior). One commonly used model for elastic-plastic behavior of powders is Drucker-Prager Cap (DPC), assuming the material as porous compressible and isotropic. The model describes the yielding of the powder as a function of hydrostatic stress $p$, the modulus of deviatoric stress $q$ (effective equivalent stress) and the relative density of the compact. A typical shape of DPC yield surface in $p-q$ plane was plotted in Fig. 1.

Briefly, the yield surface is composed of two main surfaces, $F_{s}$ and $F_{c}$ representing two different mechanisms:

a) A shear failure surface $F_{s}$, which characterizes the limit of admissible stress that can cause the compact fracture. In $\mathrm{p}-\mathrm{q}$ plane, $\mathrm{F}_{\mathrm{s}}$ is defined by the following equations:

$$
F_{s}(p, q)=q-\mathrm{p} \tan \beta-d=0
$$

where $p=\frac{1}{3} \sum \sigma_{\mathrm{kk}}$ is the hydrostatic stress, $q=\sqrt{\frac{1}{2} \mathrm{~S}_{\mathrm{ij}} \mathrm{S}_{\mathrm{ij}}}$ is the effective equivalent stress (modulus of the deviatoric stress $S_{i j}=\sigma_{i j}$ $\left.\mathrm{p} \delta_{\mathrm{ij}}\right), d$ is the powder cohesion and $\beta$ is the internal friction angle.

b) A cap yield surface, $F_{c}$, which governs the densification of the material, shows an elliptical shape and intersects the shear failure surface $\mathrm{F}_{\mathrm{s}}$ at $p=\mathrm{P}_{\mathrm{a}}$, and the hydrostatic stress axis at $p=\mathrm{P}_{\mathrm{b}}$. The distance between $P_{b}$ and $P_{a}$ is equal to $R\left(d+P_{a} \tan \beta\right)$. The equation of the cap can be written as:

$$
F_{c}(p, q)=\sqrt{\left(p-P_{a}\right)^{2}+(R \cdot q)^{2}}-R\left(d+P_{a} \tan \beta\right)=0
$$

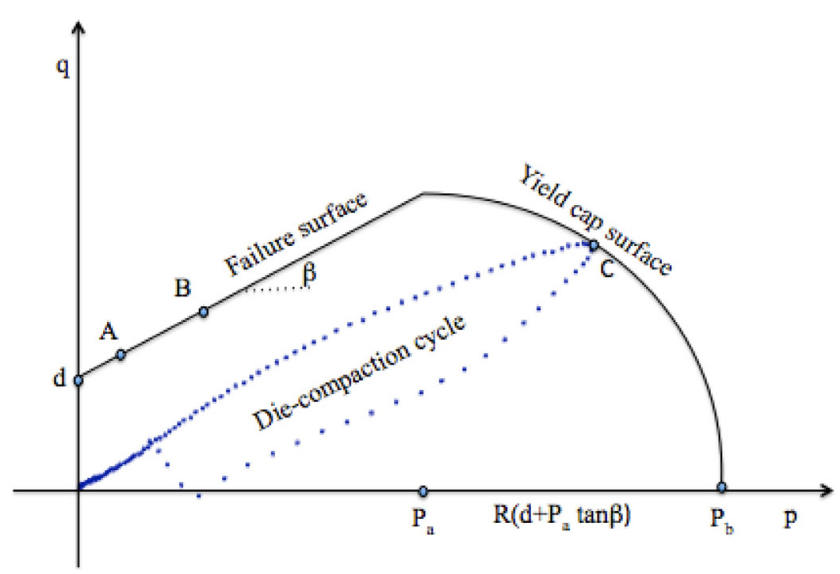

Fig. 1. DPC Yield surface in $p-q$ plane. [d: cohesion; $\beta$ : angle of internal friction; $P_{b}$ hardening function; A: diametrical strength; $\mathrm{B}$ : unconfined compression strength; $\mathrm{C}$ : maximum stress in die-compaction] where $R, d$ and $\beta$ are the eccentricity that controls the shape of the cap, the cohesion and the internal friction angle, respectively. All these parameters are density-dependent. The mechanism of increasing the density by increasing the stress induces irreversible flow of the deformation, which corresponds to the expansion of the yield surface. In the formalism of elastic plastic model, this expansion is done along the normal of the yield surface [9].

Finally, the material parameters that need to be determined based on standards experiments such as instrumented die compaction, simple compression and diametrical compression [10], are powder cohesion $\mathrm{d}$, internal friction $\beta$, eccentricity of the cap $R$ and $P_{b}$ the evolution of the cap surface according to the volumetric strain. These parameters are depending on the relative density, which is used as internal state variable. In the paragraph 3.3, the procedure of the calibration is exposed.

\section{Materials and methods}

\subsection{Powder}

A Microcrystalline cellulose powder MCC (Avicel PH101, FMC BioPolymer) was used as the feed powder for roll press to manufacture ribbons which were milled using an oscillating system to produce granules. These granules were sieved in two size classes of granules, which were further processed into tablets. Prior to compaction, the powder and granules were stored in an oven at $24^{\circ} \mathrm{C}$ for $24 \mathrm{~h}$ to eliminate the effect of the moisture gradient on the powder behavior during their processing by roll and die compaction. No lubricant was added to the powder for dry granulation. The true density of the powder was determined using a Helium pycnometer (Accupyc 1330, Micromeritics Instrument Corp., Norcross, GA, USA; $n=3$ ). The particle size distribution was determined by laser diffraction analysis (Mastersizer 3000, Malvern Instruments Ltd., Malvern, United Kingdom), fitted with a dry powder feeder. The median particle size was considered as the volume median diameter $\mathrm{d}_{(\mathrm{v}, 0.5)}$. The used bulk density was given by the manufacturer (FMC Biopolymer). These basic properties are summarized in Table 1.

\subsection{Ribbons preparation}

Ribbons of MCC 101 were produced using a laboratory roll press (Komarek® B050PH), which is equipped with a single horizontal feed screw, fixed cheek plates and smooth rolls of $100 \mathrm{~mm}$ of diameter and $38 \mathrm{~mm}$ of width. The gap was adjusted to $1.8 \mathrm{~mm}$, the roll speed was fixed to $2 \mathrm{rpm}$ and the screw speed was manually adjusted to $13.5 \mathrm{rpm}$. The ribbons produced at the first step of starting process were eliminated and only those obtained in steady state conditions were considered. The mean density of the resulting ribbons was measured using a GeoPyc ${ }^{\circledR} 1360$ Envelope Density Analyzer. Three ribbons were randomly sampled and manually cut in pieces. Therefore, pieces from all parts of the ribbon were weighted using a precision balance (CP 224S, Sartorius, Germany) and their volume measured. The operation was repeated 3 times. Then the mean density of the ribbon was calculated. Using the true density of the powder MCC 101 (Table 1.), the mean relative density of the ribbon was as $0.57 \pm 0.01$.

\subsection{Granules preparation}

The obtained ribbons were milled using an oscillating milling system (Erweka AR 402). The particle size distribution was determined by sieve

Table 1

Basic properties of MCC 101 powder

\begin{tabular}{llll}
\hline Material & $\begin{array}{l}\text { Mean particle size }\left(\mathrm{d}_{\mathrm{v}, 50}\right) \\
(\mu \mathrm{m})\end{array}$ & $\begin{array}{l}\text { Bulk density } \\
(\mathrm{g} / \mathrm{cm} 3)\end{array}$ & $\begin{array}{l}\text { True density } \\
(\mathrm{g} / \mathrm{cm} 3)\end{array}$ \\
\hline MCC 101 & $65.6 \pm 0.2$ & 0.32 & $1.5659 \pm 0.0005$ \\
\hline
\end{tabular}


analysis (AS 200 digit, Retsch, Germany) at amplitude of 40 for $20 \mathrm{~min}$. Two size classes of granules [250-500 $\mu \mathrm{m}$ ] and [1250-1600 $\mu \mathrm{m}$ ] were selected to study further the effect of the granule size on the process of die compaction. Fig. 2 shows SEM images of the powder MCC101 and a granule from each size class.

\subsection{Model calibration procedure}

\subsubsection{Cohesion and internal friction angle}

The shear failure line of the yield surface is defined by two parameters: the cohesion $d$, which is the intersection with the equivalent stress axis q, and the internal friction angle $\beta$, which is the slope of the failure line. For a given relative density of a tablet, the two material parameters are classically determined from the diametrical tensile strength $\sigma_{d}$ and the unconfined compressive strength $\sigma_{c}$ of the tablet.

For the diametrical compression test, the tensile strength and the corresponding hydrostatic pressure $p_{d}$ and deviatoric stress $q_{c}$ are computed as following:

$\sigma_{d}=\frac{2 F_{d}}{\pi D H}$

$p_{d}=\frac{2}{3} \sigma_{d} \quad q_{d}=\sqrt{13 \sigma_{d}}$

where $F_{d}$ is the force corresponding to the diametrical strength of the tablet, and $\mathrm{D}$ and $\mathrm{H}$ are the diameter and the height of the tablet, respectively.

For the axial compressive test, the strength $\sigma_{c}$ and the associate stress state in the plane $\mathrm{p}-\mathrm{q}$ are defined as follows:

$\sigma_{c}=\frac{4 F_{a c}}{\pi D^{2}}$

$p_{c}=\frac{1}{3} \sigma_{c} \quad q_{c}=\sigma_{c}$

where $F_{a c}$ is the peak axial force to break the tablet and $\mathrm{D}$ is the tablet diameter.

Once the data $\left(p_{d}, q_{d}\right)$ and $\left(p_{c}, q_{c}\right)$ are determined for a given relative density of the tablet, the shear failure line can be fitted and the cohesion $\mathrm{d}$ and the internal friction $\beta$ can be computed as following:

$d=\frac{\sigma_{c} \sigma_{d}(\sqrt{13}-2)}{\sigma_{c}-2 \sigma_{d}}$

$\beta=\tan ^{-1}\left[\frac{3\left(\sigma_{c}-d\right)}{\sigma_{c}}\right]$

(a)

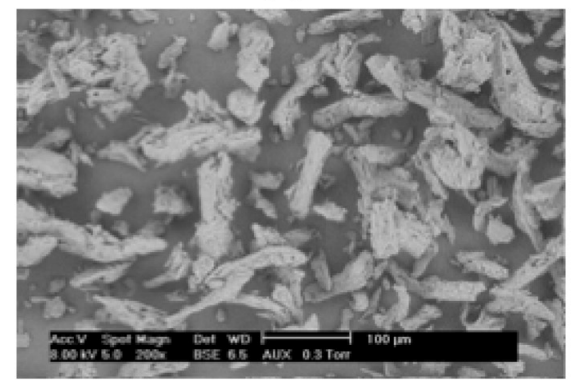

\subsubsection{Eccentricity and hardening function}

The cap surface properties are computed from the measured axial stress $\sigma_{z}$ and radial stress $\sigma_{r}$ using a fully instrumented press where the die is equipped with a strain gauge mounted on the die wall. The gauge was positioned at $1.5 \mathrm{~mm}$ from the surface of the lower punch so that at end of the compaction, the gauge is approximately positioned at the middle of tablets with height in the range 3-4 mm. A rubbery material was used for the calibration [11]. Assuming the axisymmetric conditions, the deviatoric and hydrostatic stresses are calculated as:

$p=\frac{\sigma_{z}+2 \sigma_{r}}{3}$

$q=\left|\sigma_{z}-\sigma_{r}\right|$

Then, the cap parameters are determined based on the following equations:

$R=\sqrt{\frac{2}{3 q}\left(p-P_{a}\right)}$

$P_{b}=P_{a}+R\left(d+P_{a} \tan \beta\right)$

Where $P_{a}$ is calculated as following:

$P_{a}=\frac{-3 q-4 d \tan \beta+\sqrt{9 q^{2}+24 d q \tan \beta+24 p q \tan \beta^{2}+16 q^{2} \tan \beta^{2}}}{4 \tan \beta^{2}}$

The hydrostatic yield surface $P_{b}$ defines the position of the cap surface and dependent on the volumetric strain $\varepsilon_{v o l}$ defined as:

$\varepsilon_{v o l}=\ln \left(\frac{\rho}{\rho_{0}}\right)$

where $\rho$ is the bulk density of the tablet after ejection and $\rho_{0}$ the initial density of the powder when filling the die.

\subsubsection{Tablets preparation}

The calibration of DPC model requires the preparation of tables with different aspect ratios.

First, tablets were manufactured at different densities using a fully instrumented eccentric uniaxial press (Frogerais OA, France). The press is equipped with a fixed cylindrical die of $11.28 \mathrm{~mm}$ of diameter and $10 \mathrm{~mm}$ of height. The pressure is applied with the upper punch and the ejection is executed with the lower one. The press is also instrumented with five sensors that allow the measurement of the displacements of the upper and lower punches, the applied axial pressure $\left(\sigma_{\mathrm{u}}\right)$, the transmitted axial pressure to the lower punch $\left(\sigma_{1}\right)$ and the radial stress on the die wall $\left(\sigma_{\mathrm{r}}\right)$. The tablets were prepared by automatically filling the powder mass, which varies from 0.30 for feed powder to

(b)

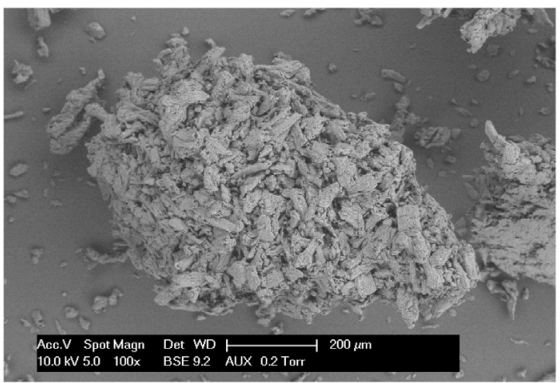

(c)

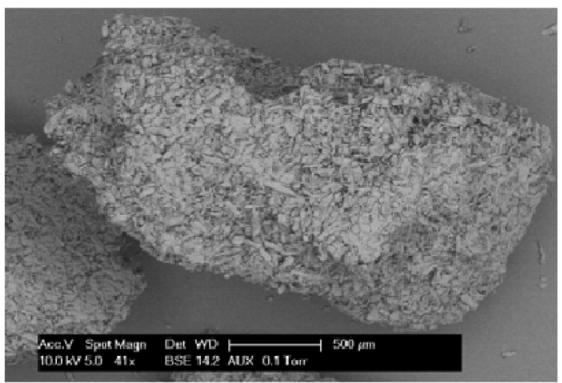

Fig. 2. SEM images of powders: (a) MCC 101; (b) granules [250-500 $\mu \mathrm{m}$ ] and (c) granules [1250-1600 $\mu \mathrm{m}]$. 
0.33 for big granules. The die was beforehand lubricated compacting the magnesium stearate powder. Compaction cycles and measurement of axial, radial stress and axial displacement were

According to the guideline proposed by Doremus et al. [12], for the diametrical compression test, tablets with an aspect ratio $\frac{H}{D} \leq 0.25$ should be produced. Also, the test is considered valid when the failure fracture is originated at the center of the specimen. However, for the axial compression test, an aspect ratio $\frac{H}{D} \geq 2$ is recommended. In this case, it is also important to ensure a desired failure path at $45^{\circ} \mathrm{C}$ and only specimens with a fracture at $45^{\circ} \mathrm{C}$ were considered as valid results (At low tablet density, the breakage of the tablets sometimes occurred at the edges of the tablets and these specimens were not considered as valid).

According to the above specifications, tablets from powder MCC101 and granules were produced using a uniaxial press (Instron ${ }^{\circledR}$ press) equipped with flat face punches of $11.28 \mathrm{~mm}$ of diameter at a compaction speed of $5 \mathrm{~mm} / \mathrm{min}$. In order to reduce the density variation along the height, the die was lubricated by compacting magnesium stearate powder before proceeding to the compaction of the sample of MCC.

For diametrical compression test, series of cylindrical flat tablets from the three types of powders, were prepared by filling a powder mass of $0.350 \pm 0.005 \mathrm{~g}$ into the die (height of $10 \mathrm{~mm}$ ) and varying the compaction pressure in the range $10-120 \mathrm{MPa}$. The resulting relative densities of the tablets were in the interval $[0.5,0.9]$. For the axial compression test, tablets of $22 \mathrm{~mm}$ of thickness were prepared in a die of $11.28 \mathrm{~mm}$ of diameter and $90 \mathrm{~mm}$ of height varying the filling powder mass. The resulted relative densities were in the interval [0.4, $0.9]$.

The diametrical and axial strengths of tablets were measured using an Instron press (Instron 5576). The failure force (maximum of force to break the tablet) was considered for the computation of the tablet strength. In order to reduce the density variation along the height, the die was lubricated by compacting magnesium stearate powder before proceeding to the compaction of the sample of MCC. For all powders, the measurements were repeated three times for each relative density. For later determination of shear failure parameters at low densities, experimental results of diametrical and axial strengths were fitted in exponential regressions.

\section{Results and discussions}

\subsection{Densification of granules}

The Fig. 3 shows optical images of tablets prepared at different relative densities using the granules of size ranges [250-500 $\mu \mathrm{m}]$ and [1250-1600 $\mu \mathrm{m}]$. The images concern the top and the side views of the tablets. It can be observed, at low relative density ( 0.4 and 0.5 ), rough surfaces where the granules boundaries can be distinguished, mainly for the large granules. Indeed, at this level of compaction, the granules have passed the stage of rearrangement and start to deform plastically. On the other hand, at higher density, the surfaces become smoother and more homogeneous. At a relative density of 0.8 and 0.9 , the granular structure is not visible. This suggests that, after first deformation, the granules fractured into smaller particles that were again rearranged filling the voids and deformed, as described in the literature [7]. Similar images were obtained by Mitra et al. [8] for tablets of 0.69 of relative density, prepared from mini-tablets compacted at different solid fraction. The observed roughness was a signature of the effect of the hardness of the mini-tablets used in the compaction.

\subsection{Cohesion and internal friction}

To determine the shear failure line of DPC model and to calculate the cohesion and the angle internal friction parameters, the uniaxial and diametrical strengths of tablets were obtained. In Figs. 4 and 5, the

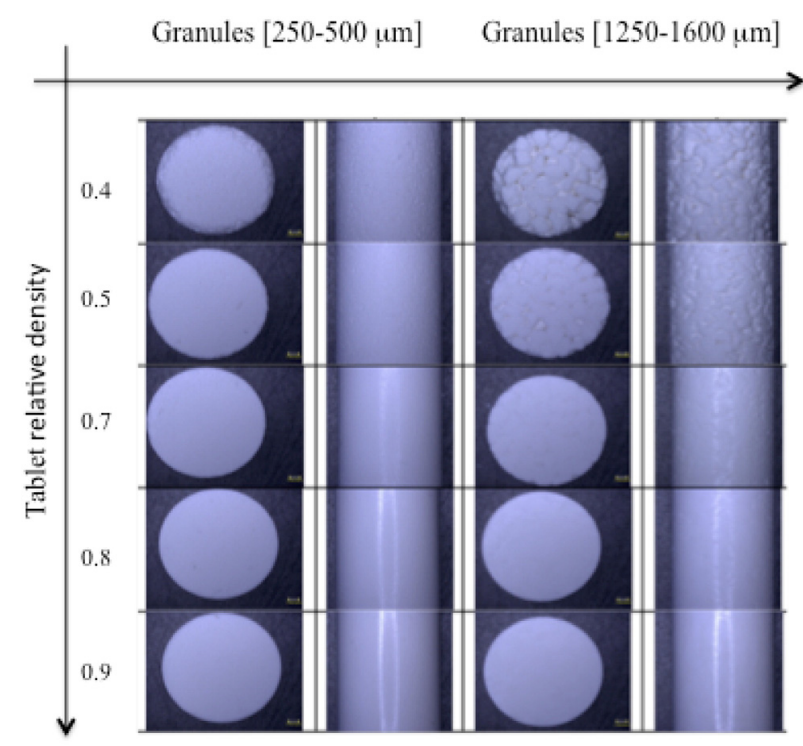

Fig. 3. Optical images of tablets at different relative density with effect of size granules.

uniaxial and the diametrical tablet strength were plotted according to the relative density for the feed powder and the granules.

Overall, tablet strength increases with the increase of the relative density. The strength of tablets from feed powder is higher than the strength of tablets from granules. This observation is supported by the literature [2] [5]. On the another hand, the effect of granule size did not show a significant difference on both strengths as both granule size were obtained from the milling of the same ribbons that were compacted under the same conditions (roll-compaction pressure). The effect of the granules solid fraction on the tablet's strength was reported in the literature, but not studied in this work. The reduction of tablet tensile strength with roll specific compaction forces, which increases ribbon density and hence granules density, was showed in [5]. This behavior was also demonstrated in the work of Mitral et al. [8]. Preparing tablets with mono-sized granules (mini-tablets), the authors showed the decrease of tablet strength with the increase of the granules solid fraction.

For uniaxial compression, it was possible to reach densities lower than 0.4 due to the dimensions of the tablets ( $22 \mathrm{~mm}$ of height),

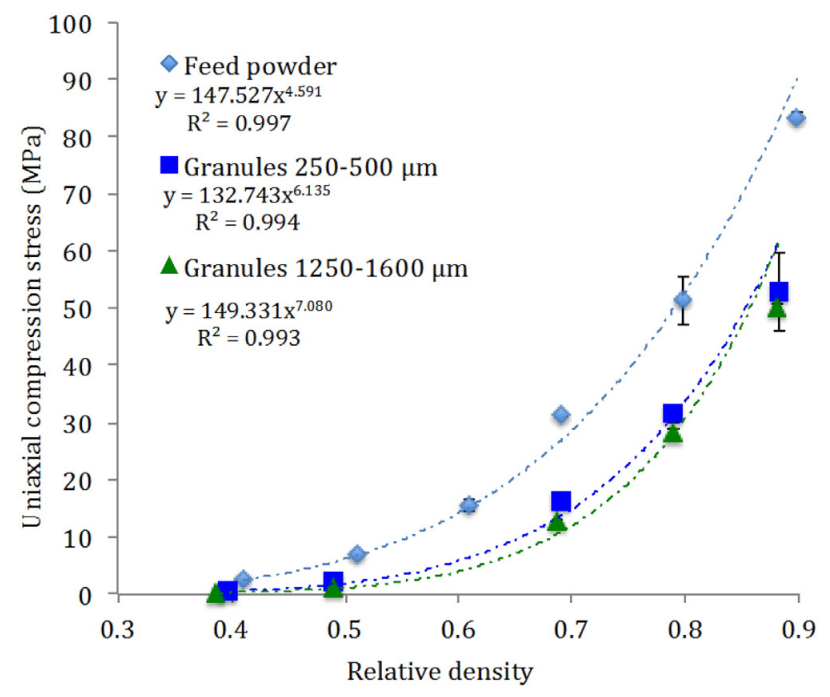

Fig. 4. Uniaxial strength versus relative density. 


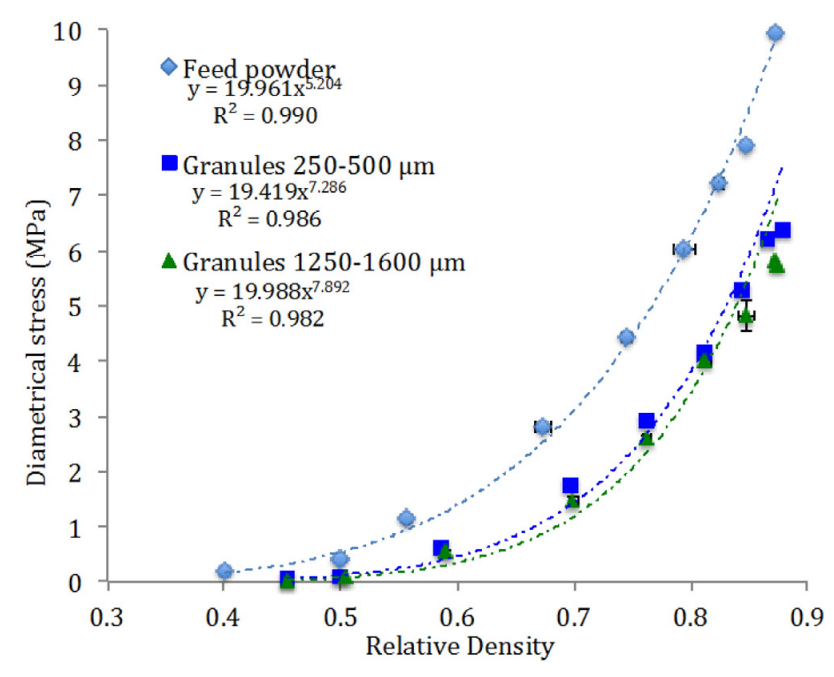

Fig. 5. Diametrical strength vs. relative density.

which give tablets strong enough to be handled. On the other hand, for diametrical test, the tablets were compacted at different compaction pressures, being the minimum pressure $10 \mathrm{MPa}$, which gave minimum relative densities of 0.46 for the powder and 0.50 for the granules.

In order to compute in analytical manner the evolution of the shear failure parameters in the range of relatives densities of $0.5-0.9$, the experimental data plotted in Figs. 4 and 5 were interpolated by fitting exponential regressions. These fittings are included in the graphs and they all show high accuracy $\left(R^{2} \geq 0.98\right)$.

The shear failure parameters (cohesion and internal friction angle) were obtained using eqs. (7) and (8). In the Figs. 6 and 7 the cohesion and angle of friction were plotted for the three category of powders (feed powders, small granules and large granules) as a function of the tablet relative density.

It is shown that the cohesion, $\mathrm{d}$, increased exponentially when the relative density of tablets is increased. Nevertheless, it is decreased when the granules size is increased, although the difference of values for different granule size is not really significant.

In the same way as the cohesion, the angle of internal friction $\beta$ is plotted against the tablet relative density (Fig. 7). The internal friction angle shows a value of approximately $70^{\circ}$, with a slight decrease when the relative density increases. This is classical value reported in the literature, in general constant and in the range from around $60^{\circ}$

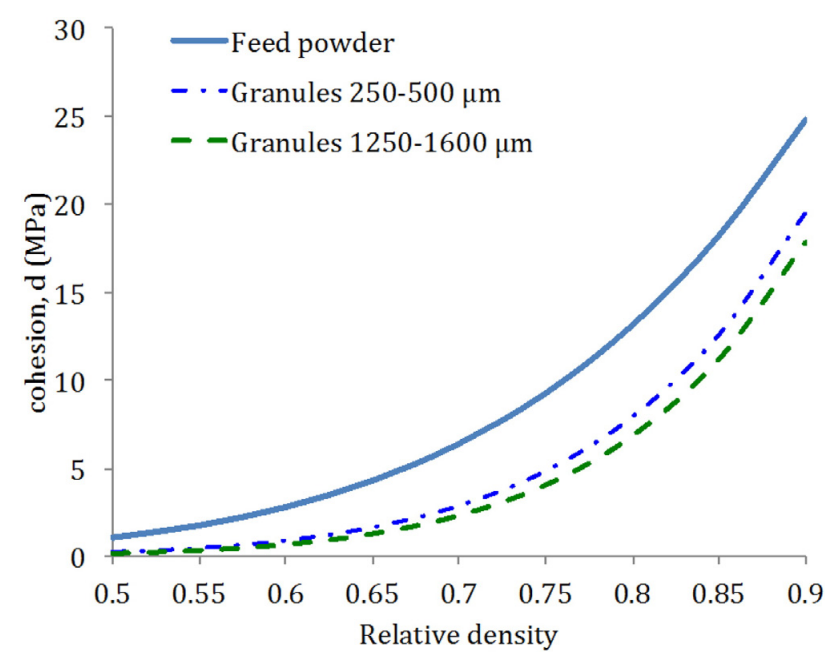

Fig. 6. Cohesion, d.

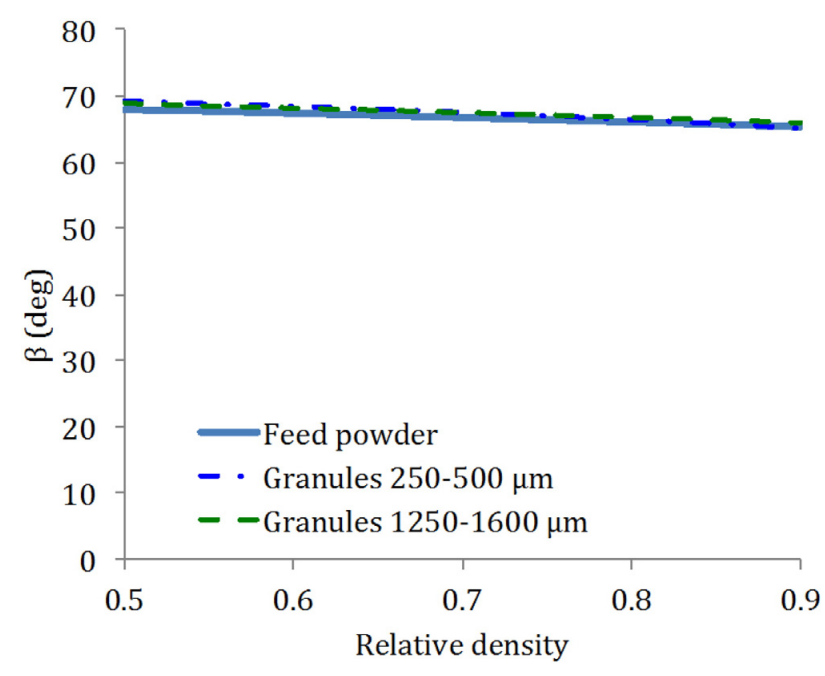

Fig. 7. Angle of internal friction, $\beta$.

to $70^{\circ}$ either for a metal or pharmaceutical materials [13-15]. It was not found a difference between the feed powder and the granules and the evolution of the angle of internal friction is overlapping for all of them.

The shear failure parameters for virgin powder and granules prepared from mini-tablets with different solid fraction were also analyzed in the work of Mitra et al. [8]. They showed that the cohesion was higher for the virgin powder than for the granules and decreased as the granule solid fraction decreased. Moreover, no variation was observed for the angle of internal friction, resulting independent of the granule solid fraction or the tablet density, which is in agreement with our results.

\subsection{Cap parameters}

The measured axial stress $\sigma_{z}$ and radial stress $\sigma_{r}$ were recorded and the components of the stress ( $p$ and $q$ ) were calculated based on eqs. (9) and (10). In Fig. 8, both components of the stress are plotted as a function of the tablet relative density. Here, it can be observed that both, the hydrostatic stress and the equivalent stress increase with the increase of the relative density. However, their values decrease when increasing the granule size. Moreover, the differences are more relevant for the hydrostatic stress, which means that the effect of the increase of granule size is predominant for the hydrostatic stress over the equivalent stress.

The cap surface properties (eccentricity of the cap, $R$, and the hydrostatic yield strength $P_{b}$ ) are computed from $p$ and $q$ based on the eqs. (11), (12) and (13). In Fig. 9 the results of cap eccentricity $R$ against the tablet relative density were plotted. Fig. 10 shows the results of yield hardening function $\mathrm{P}_{\mathrm{b}}$ against the tablet relative density.

It can be observed (Fig. 9), that $R$ varied from 0.7 to 0.95 , reaching the highest values for the feed powder compared to the granules. For MCC, similar values were reported in the literature [16-19]. The eccentricity controls the ratio of hydrostatic stress to shear stress required to densify a compact. It can be observed, in Fig. 9, that the evolution of the eccentricity shows two tendencies. At low tablet relative density, the eccentricity slightly decreases when increasing the density. However, at low density, there is no significant effect of the granule size on the values of $R$. Similar evolution of the eccentricity was found in [20] for the compaction of zirconia $\left(\mathrm{ZrO}_{2}\right)$ powder, although there was a high dispersion of their data at low density and the evolution was fitted to a linear equation. In the range of relative density $0.6-0.9$, the eccentricity increases with the relative density and shows lower values for larger granules. This means that the impact of shear stress in the compaction is less dominant in granulated material than in raw material. 

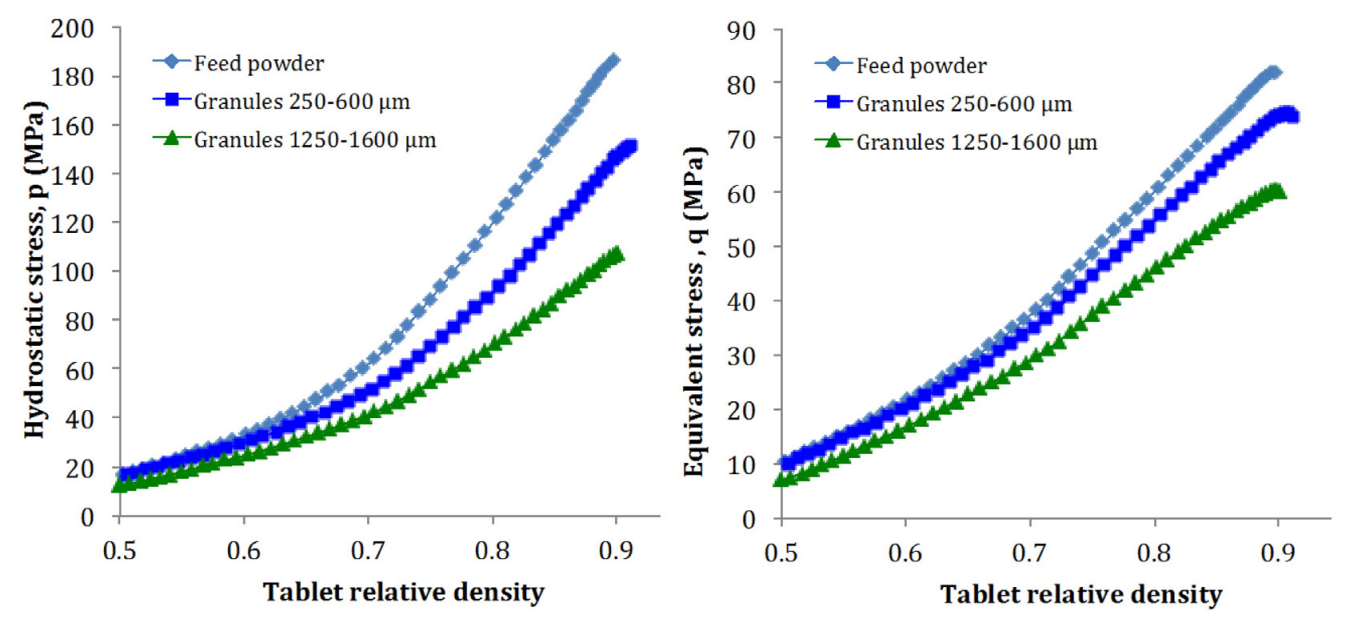

Fig. 8. Components of the stress versus the tablet relative density: (a) Hydrostatic stress, p; (b) Equivalent stress, q.

Regarding the yield function $P_{b}$, plotted in Fig. 10, the values increase exponentially when the tablet density increases. It can be observed also that $P_{b}$ decreases significantly when the granule size increases. This means that it becomes necessary to apply a greater pressure on the feed powder than on the granules in order to achieve the same plastic deformation (or relative density).

However, these differences of $P_{b}$ between the feed powder and the granules, were not found in [8] where $\mathrm{P}_{\mathrm{b}}$ was not significantly impacted by the dry granulation or the solid fraction of the granules.

\subsection{Iso-density yield surfaces}

The parameters obtained in the previous sections were compiled and the DPC yield surfaces in the plane $p$ - $q$ were plotted. First, the isodensity yield surfaces for the feed powder and the granules are plotted in Fig. 11. As expected, for the three types of particulate materials (feed powder and granules of 250-500 and 1250-1600 $\mu \mathrm{m}$ ), when relative density increases, the yield surface expands in the stress space, which means a greater resistance to further plastic deformation.

The curves are not self- similar, due to the variation of the parameters such as cohesion, which increase during compaction for all the materials (Cunningham et al., 2004). In the same manner, there is an evolution of the shape and size of the ellipse (determined by the variation of $R$ and $P_{b}$ ). It can be observed the maximum hydrostatic pressure

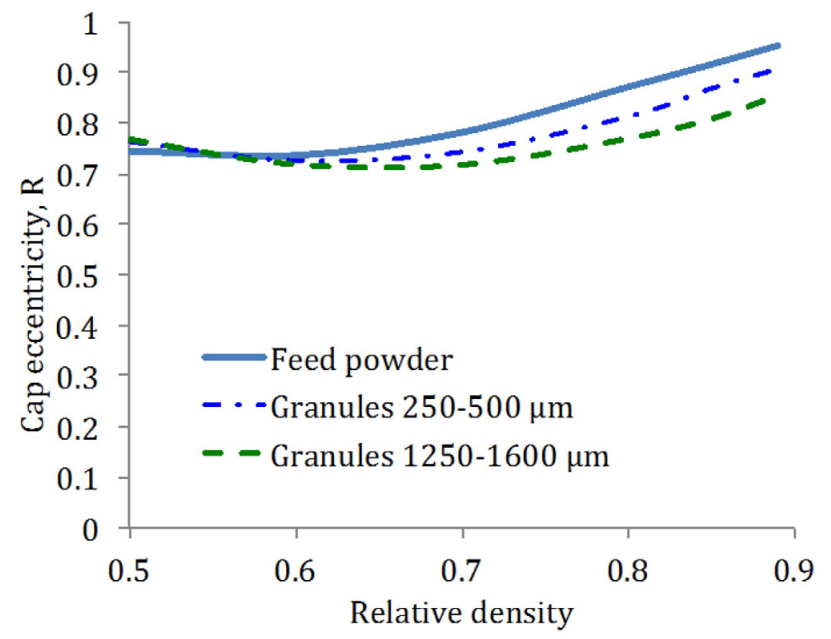

Fig. 9. Cap eccentricity versus relative density. decrease from feed powder (172 MPa) to granules (160 MPa for granules of $250-500 \mu \mathrm{m}$ and $120 \mathrm{MPa}$ for granules of $1250-1600 \mu \mathrm{m}$ ).

For the relative densities examined, the DPC parameters for feed powder and granules showed to be density-dependent, which will have impact on the shape of the yield surfaces. For this reason, the yield surfaces of the three material are plotted together at two different tablet densities: $\mathrm{RD}=0.5$ (low density) and $\mathrm{RD}=0.9$ (high density) in Fig. 12a and 12b. This allows us to compare the results considering low and high density and see if under these states of stresses the behaviors differ. It can be observed that, for both densities, the granules have smaller yield surface than the feed powder. Moreover, when the granule size increases, the yield surface contracts. For the granules, the yielded (flowing) region is smaller than for the feed powder. This means that, not all the materials required the same stress to produce tablets with the same density. A higher stress needs to be applied to the feed powder in order to deform it. The granulated powders underwent a loading history due to the roll-compaction pressure applied in the previous step. This complex loading corresponded to a history of plastic deformation in the powder. The granulated material is then in a hardened state. During die compaction of the granules, the development of the deformation under compressive loading depends on such history. Therefore, the feed powder and the granules are not in the same initial state of hardening. Then, it becomes necessary to apply a greater pressure on the feed powder than on the granules in order to achieve the same plastic deformation (or relative density).

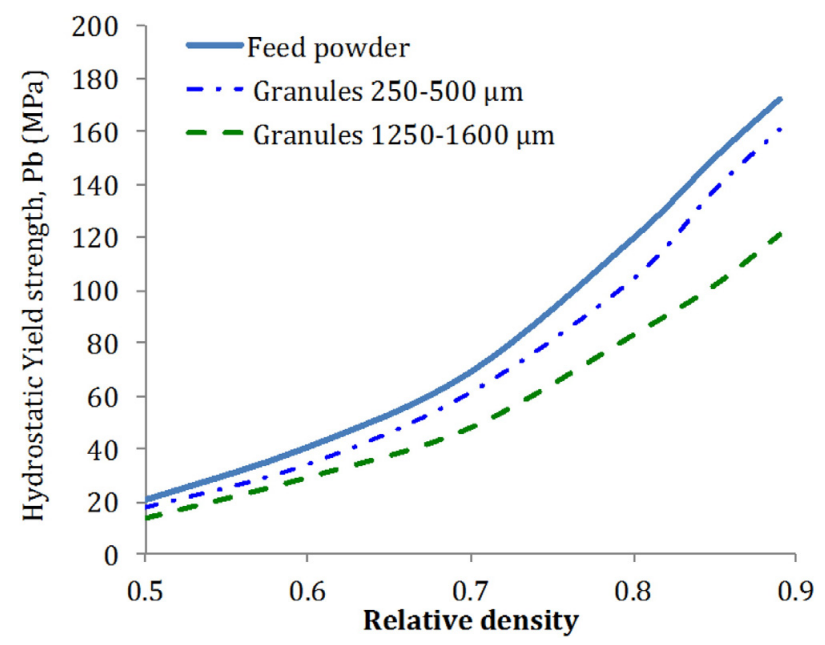

Fig. 10. Hardening function versus relative density. 


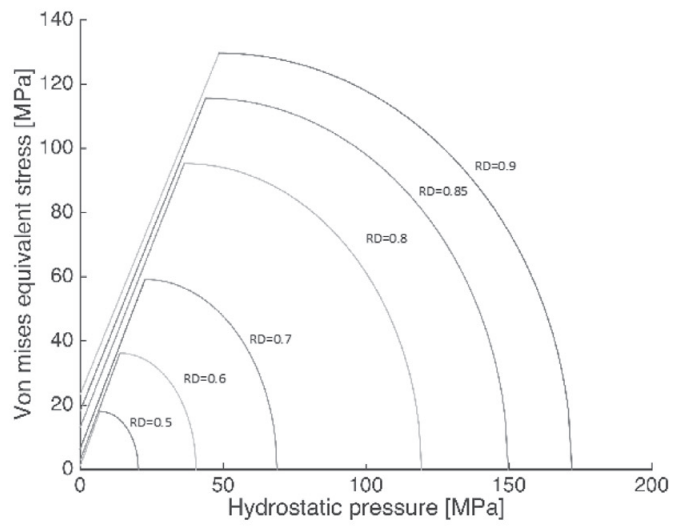

(b) Granules 250-500 $\mu \mathrm{m}$

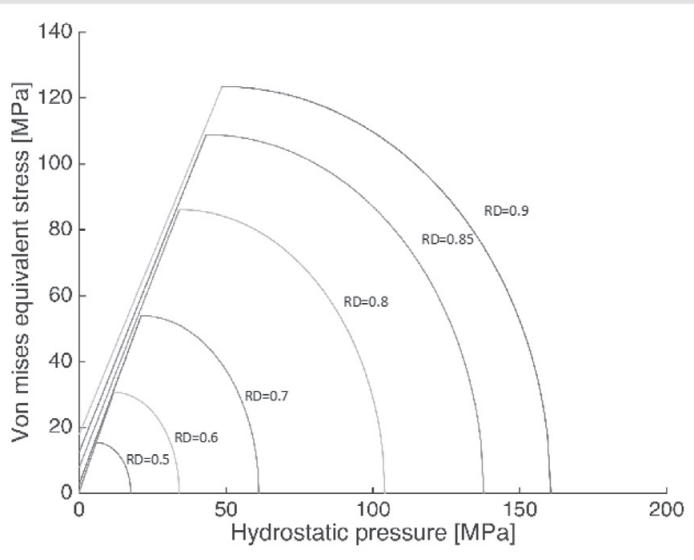

(c) Granules 1250-1600 $\mu \mathrm{m}$

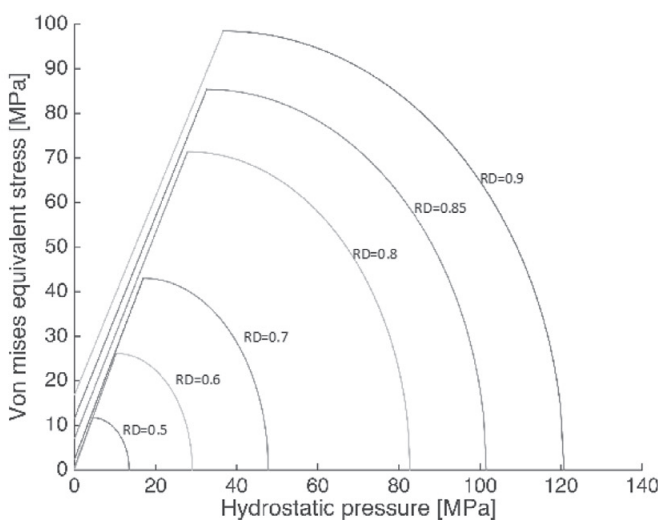

Fig. 11. Iso-density yield surfaces for different tablet densities for (a) feed powder, (b) Granules 250-500 $\mu \mathrm{m}$ and (c) Granules $1250-1600 \mu \mathrm{m}$.

Regarding the shear failure line, it can be observed that, at high density, it is overlapping (same cohesion and internal friction) for both sizes of granules, while, for feed powder, the line has the same slope but different cohesion. This is, at high relative density, the only parameter differing in the shear failure is the cohesion and not the angle of internal friction. For both densities, the shear failure line for feed powder is over the granules' lines, which that tablets produced with feed powder can resist higher stress before fracture.

In contrast to our results, Mitra et al., [8] found that the yield cap curves for all the materials (feed powder and granules) were overlapping for the same tablet density. The feed powder and granules required the same stress to reach a certain tablet density. Nevertheless, the used granules were mono-sized mini-tablets with higher density than the roll-compacted granules used in this study.

\section{Conclusions}

The goal of this work was to investigate the die-compaction behavior of dry granulated material in order to better understanding the effect of roll-compaction and the granule size. This behavior was compared to that of the non-granulated powder and the analysis was based on the identification of the main material properties taken into account into DPC model. The study was conducted on MCC 101, using standard methodology for the model calibration (die compression, diametrical tensile strength and unconfined axial strength). Material properties such as cohesion, angle of friction, eccentricity and yield hardening function were determined according to the relative density.
Overall, the results showed that all the material properties were density-dependent and the values of the DPC parameters were higher for feed powder than for granulated powder. Regarding the shear failure parameters, the cohesion increased exponentially when the relative density of tablets is increased. Nevertheless, it decreases when the granules size is increased. However, the internal friction angle shows a value of approximately $70^{\circ}$, with a slight decrease when the relative density increases. For the cap parameters, it was found that the eccentricity slightly decreases at low tablet density (0.5), but it increases in the range of relative density $(0.6-0.9)$. The yield function $P_{b}$ increases exponentially when the tablet density increases. These results point out that, for a given density of tablets (i) the yield hydrostatic pressure $(\mathrm{Pb})$ needed to develop plastic deformation in the material is lower for granulated material than raw material, (ii) the impact of shear stress in the compaction is less dominant in granulated material than in raw material (shape of the cap R) and finally (iii) when the granule size increases, the effect of $\mathrm{P}_{\mathrm{b}}$ and shear are less dominant (comparatively to raw material for equivalent density).

These differences of values of the DPC parameters gave as a result different yield surfaces and for the range of densities studied, the granules have smaller yield surface than the feed powder.

\section{Acknowledgement}

This project has received funding from the European Union's Seventh Framework Programme for research, technological development and demonstration under grant agreement No. 316555. 

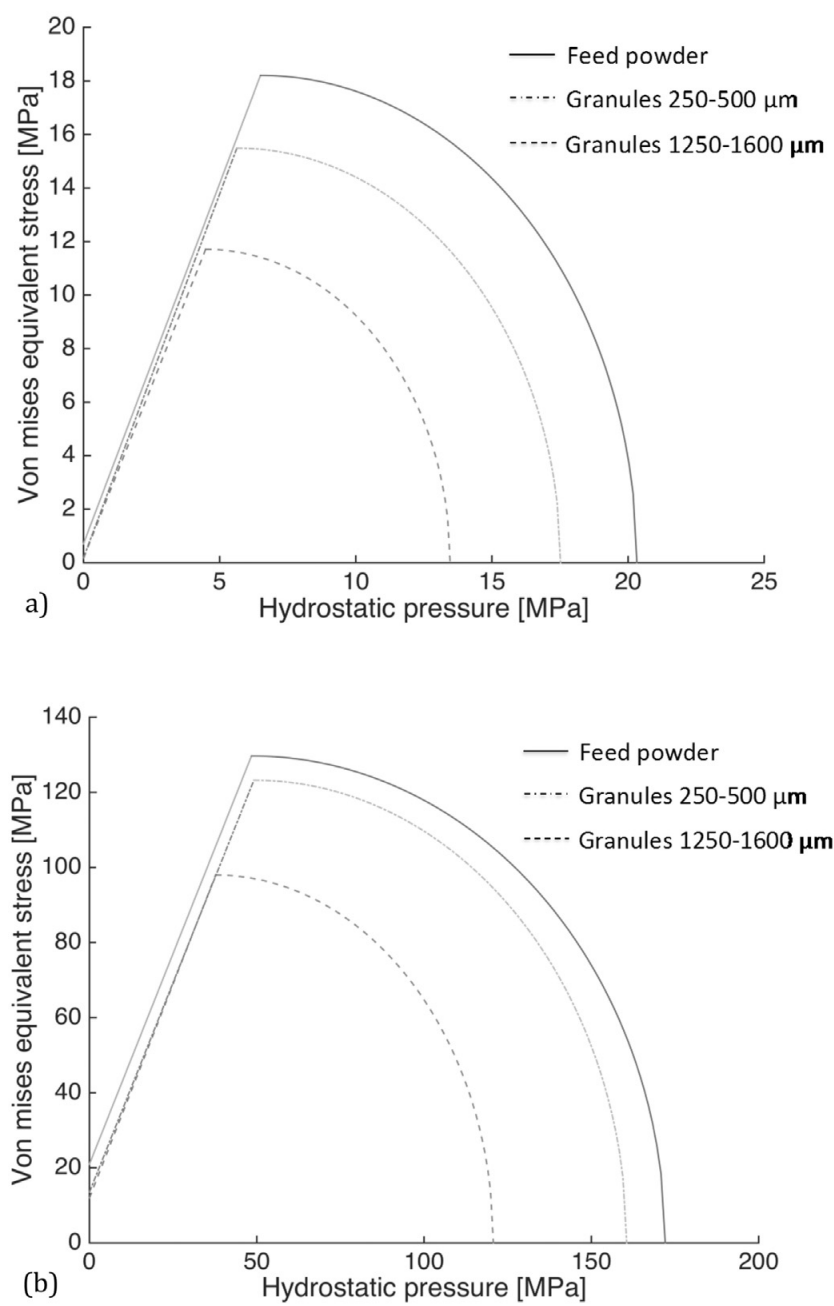

Fig. 12. Yield surfaces at different relative densities (RD): (a) $R D=0.5$; (b) $R D=0.9$.

\section{References}

[1] R.W. Miller, Roller Compaction Technology, in: D.M. Parikh (Ed.), Handbook of pharmaceutical Granulation Technology, Taylor \& Francis Group, London, 2005.
[2] S. Malkowska, K.A. Khan, Effect of recompression on the properties of tablets prepared by dry granulation, Drug Dev. Ind. Pharm. 9 (1983) 331-347.

[3] M.A. Falzone, E.P. Garnet, G.P. Mccabe, Effects of changes in roller compactor parameters on granulations produced by compaction, Drug Dev. Ind. Pharm. 18 (1992 469-489.

[4] S. Changquan, M.W. Himmelspach, Reduced tabletability of roller compacted granules as a result of granule size enlargement, J. Pharm. Sci. 95 (2006) 200-206.

[5] M.G. Herting, P. Kleinebudde, Studies on the reduction of tensile strength of tablets after roll compaction/dry granulation, Eur. J. Pharm. Biopharm. 70 (2008) 372-379.

[6] T. Kennedy, S. Hampshire, Y. Yaginuma, A study of the compaction mechanism of granulated materials, J. Eur. Ceram. Soc. 17 (1997) 133-139.

[7] K. Kondoh, R. Watanabe, H. Hashimoto, Analysis of compaction behaviour of wet granulated aluminium alloy powder, Powder Metall. 43 (2000) 359-363.

[8] B. Mitra, J. Hilden, J.D. Litster, Compaction mechanics of plastically deformable dry granules, Powder Technol. 291 (2016) 328-336.

[9] A. Michrafy, D. Ringenbacher, P. Tcheroloff, Modelling the compaction behaviour of powders : application to pharmaceutical powders, Powder Technol. 127 (2002) 257-266.

[10] V. Bonnefoy, P. Doremus, Guidelines for modeling cold compaction behaviour of various powders, Powder Metall. 47 (2004) 285-290.

[11] A. Michrafy, H. Diarra, J.A. Dodds, Compaction behaviour of binary tablets, Powder Technol. 190 (2009) 146-151.

[12] P. Doremus, Model Input data -Failure, Modelling of Powder Die Compaction, Springer-Verlag, London, 2008 95-103.

13] L.H. Han, J.A. Elliott, A.C. Bentham, A. Mills, G.E. Amidon, B.C. Hancock, A modified drucker-prager Cap model for die compaction simulation of pharmaceutical powders, Int. J. Solids Struct. 45 (2008) 3088-3106.

[14] M.S. Kadiri, A. Michrafy, The effect of punch's shape on die compaction of pharmaceutical powders, Powder Technol. 239 (2013) 467-777.

[15] A. Krok, M. Peciar, R. Fekete, Numerical investigation into the influence of the punch shape on the mechanical behavior of pharmaceutical powders during compaction, Particuology, Chinese Society of Particuology 16 (2014) 116-131.

[16] J.C. Cunningham, I.C. Sinka, A. Zavaliangos, Analysis of tablet compaction, I. Characterization of mechanical behavior of powder and powder/tooling friction, J. Pharm. Sci. 93 (2004) 2022-2039.

[17] K. LaMarche, D. Buckley, R. Hartley, F. Qian, S. Badawy, Assessing materials' tablet compaction properties using the Drucker-Prager cap model, Powder Technol. 267 (2014) 208-220.

[18] S. Garner, J. Strong, A. Zavaliangos, The extrapolation of the Drucker-Prager/cap material parameters to low and high relative densities, Powder Technol. 283 (2015) 210-226.

[19] A. Mazor, L. Perez-Gandarillas, A. de Ryck, A. Michrafy, Effect of roll compactor sealing system designs: a finite element analysis, Powder Technol. 289 (2016) 21-30.

[20] Pr. Brewin, O. Coube, P. Doremus, Modelling of Powder Die Compaction, Springer, 2008 